\title{
Patient characteristics, clinical manifestations, prognosis, and factors associated with gastrointestinal cytomegalovirus infection in immunocompetent patients
}

Thanaboon Chaemsupaphan ${ }^{1}$, Julajak Limsrivilai i* (D, Chenchira Thongdee1, Asawin Sudcharoen?', Ananya Pongpaibul ${ }^{2}$, Nonthalee Pausawasdi ${ }^{1}$ and Phunchai Charatcharoenwitthaya ${ }^{1}$

\begin{abstract}
Background: Gastrointestinal (GI) cytomegaloviral (CMV) infection is common among patients with immunocompromised status; however, data specific to GI-CMV infection in immunocompetent patients are comparatively limited.

Methods: This retrospective study included patients diagnosed with GI-CMV infection at Siriraj Hospital (Bangkok, Thailand) during 2008-2017. Baseline characteristics, presentations, comorbid conditions, endoscopic findings, treatments, and outcomes were compared between immunocompetent and immunocompromised.

Results: One hundred and seventy-three patients (56 immunocompetent, 117 immunocompromised) were included. Immunocompetent patients were significantly older than immunocompromised patients (73 vs. 48.6 years, $p<0.0001)$. Significantly more immunocompetent patients were in the ICU at the time of diagnosis (21.0\% vs. 8.6\%, $p=0.024)$. GI bleeding was the leading presentation in immunocompetent, while diarrhea and abdominal pain were more common in immunocompromised. Blood CMV viral load was negative in significantly more immunocompetent than immunocompromised (40.7\% vs. $12.9 \%, p=0.002)$. Ganciclovir was the main treatment in both groups. Significantly more immunocompetent than immunocompromised did not receive any specific therapy (25.5\% vs. 4.4\%, $p \leq 0.01)$. Six-month mortality was significantly higher among immunocompetent patients (39.0\% vs. $22.0 \%, p=0.047)$. Independent predictors of death were old age and inpatient or ICU clinical setting. Treatment with antiviral agents was the only independent protective factor.
\end{abstract}

Conclusion: GI-CMV infection was frequently observed among immunocompetent elderly patients with comorbidities or severe concomitant illnesses. Gl bleeding was the most common presentation. Blood CMV viral load was not diagnostically helpful. Significantly higher mortality was observed in immunocompetent than in immunocompromised patients, but this could be due to more severe concomitant illnesses in the immunocompetent group.

Keywords: Cytomegalovirus, Gastrointestinal, Immunocompetent, Immunocompromised

\footnotetext{
*Correspondence: alimsrivilai@gmail.com

'Division of Gastroenterology, Department of Medicine, Faculty of Medicine

Siriraj Hospital, Mahidol University, Bangkok, Thailand

Full list of author information is available at the end of the article
}

C The Author(s). 2020 Open Access This article is distributed under the terms of the Creative Commons Attribution 4.0 International License (http://creativecommons.org/licenses/by/4.0/), which permits unrestricted use, distribution, and reproduction in any medium, provided you give appropriate credit to the original author(s) and the source, provide a link to the Creative Commons license, and indicate if changes were made. The Creative Commons Public Domain Dedication waiver (http://creativecommons.org/publicdomain/zero/1.0/) applies to the data made available in this article, unless otherwise stated. 


\section{Introduction}

Cytomegalovirus (CMV) is a double-stranded DNA virus in the herpes virus family [1]. CMV is considered an important opportunistic virus among immunocompromised individuals. Patients with human immunodeficiency virus (HIV) infection, immunosuppressive state, longterm steroid or immunomodulator use, and/or organ transplantation are more susceptible to this opportunistic pathogen [2-4]. CMV infection can affect several organs, but gastrointestinal (GI) involvement is one of the most common [5]. GI-CMV manifestations include dysphagia, abdominal pain, diarrhea, and upper or lower GI bleeding [3]. GI-CMV infection in immunocompetent patients was at one time rare; however, there has been an increasing number of case reports and case series of GI-CMV infection in immunocompetent patients, especially among the elderly and critically ill patients [6-28]. Nevertheless, data specific to GI-CMV infection in immunocompetent patients are still quite limited. Only three cohorts comprehensively described risk factors, clinical manifestations, and clinical course [7, 27, 28], and one of those studies included patients taking corticosteroids [27]. This could lead to disease underrecognition, which could result in diagnostic delay and poorer outcomes. Enhanced understanding of GI-CMV infection in immunocompetent patients will improve diagnosis, treatment, and patient outcomes.

Accordingly, the aim of this study was to investigate patient characteristics, clinical manifestations, outcomes and prognoses, and factors associated with GI-CMV infection in immunocompetent patients by comparing those parameters with those of GI-CMV infection patients with immunocompromised status.

\section{Materials and methods}

This retrospective study included patients diagnosed with GI-CMV infection at the Division of Gastroenterology, Department of Medicine, Faculty of Medicine Siriraj Hospital, Mahidol University, Bangkok, Thailand during the January 2008 to December 2017 study period. Siriraj Hospital is Thailand's largest national tertiary referral center. Cases of GI-CMV infection were identified from the database of the Department of Pathology, Faculty of Medicine Siriraj Hospital, Mahidol University. Only cases with diagnostic confirmation by demonstration of either CMV viral inclusion by hematoxylin and eosin (H\&E) staining or by positive immunohistochemistry staining for CMV antigen on pathologic tissue specimens obtained from either endoscopy or surgery were included [29]. Patient demographics, comorbidities, clinical presentations, laboratory investigations (including blood CMV viral load), endoscopic and imaging findings, treatments, and outcomes were collected, recorded, and analyzed. The test for blood CMV viral load was the $\mathrm{COBAS}^{\circ}$ AmpliPrep/COBAS ${ }^{\circ} \mathrm{TaqMan}^{\circ} \mathrm{CMV}$ Test
(Roche Molecular System, Inc. USA) which has the range of detection of $150-10,000,000$ copies $/ \mathrm{mL}$. The protocol for this study was approved by the Siriraj Institutional Review Board (SiRB) on 7 September 2018 (COA no. 566/ 2561). The requirement to obtain written informed consent from included patients was waived due to the anonymous retrospective nature of this study.

\section{Definition of immune status}

Patients were separated into either the immunocompromised group or the immunocompetent group. Patients with AIDS, with organ transplantation, and/or receiving chemotherapy, systemic corticosteroids, or immunosuppressive agents were defined as immunocompromised in previous reports [7, 30, 31]. All other patients were considered to be immunocompetent.

\section{Literature review}

A PubMed search was performed from its inception to July 2018 to identify/describe the characteristics of GICMV disease in immunocompetent patients. Only articles in English were included. The term used for this search were "cytomegalovirus" AND ("gastrointestinal" OR "intestinal" OR "colitis") AND "immunocompetent". Eligible articles were reviewed by 2 investigators (JL and $\mathrm{CT})$. Disagreements between investigators were resolved by consensus. In cases where consensus could not be reached, a third investigator (PC) would determine the decision outcome. Only cohorts with at least 10 cases were selected for comparison with our data.

\section{Statistical analysis}

Descriptive statistics were used to summarize patient characteristics. Continuous variables are expressed as median and range or mean \pm standard deviation, and categorical variables are presented as number of subjects and percentage. Standard two-group comparison methods were used, including independent $t$-test or Wilcoxon rank-sum test for continuous data, and chi-square test or Fisher's exact test for categorical data. Mortality rate was compared using log-rank test. Multivariate analysis for factors that significantly predict mortality was performed using Cox regression analysis. A two-tailed $p$-value of $<$ 0.05 was considered significant for all analyses. All analyses were performed using SAS version 9.4 (SAS Institute, Inc., Cary, North Carolina, USA).

\section{Results}

From January 2008 to December 2017, 173 patients with GI-CMV disease were identified, including 56 (32.3\%) immunocompetent and 117 (67.7\%) immunocompromised patients. Of the 117 immunocompromised patients, 34 (29.1\%) had HIV infection with a median CD4 count of 19 cells $/ \mathrm{mm}^{3}$ (range: $\left.1-187\right), 24$ (20.5\%) had organ 
transplantations, 21 (17.9\%) had cancers requiring chemotherapy, $30(25.6 \%)$ and 10 (8.6\%) had autoimmune diseases and inflammatory bowel disease (IBD) requiring corticosteroids or immunosuppressive agents, respectively, and 8 had other conditions requiring corticosteroids including 2 with chronic respiratory diseases, 2 with undiagnosed enteritis, 2 with hematologic malignancies but received only palliative corticosteroids not chemotherapy, 1 with sepsis, and the other one with adrenal insufficiency. Ten patients had two underlying condition including 4 with glomerulonephritis undergoing renal transplantation, 3 with hematologic malignancies undergoing bone marrow transplantation, one with HIV and ITP, one with UC and autoimmune hemolytic anemia, and one with malignant thymoma and myasthenia gravis. The medications used among the immunocompromised patients included corticosteroids in 70 (40.5\%) patients, immunosuppressive agents in 44 (37.6\%) patients, and chemotherapy in 21 (18.0\%) patients. Two immunocompetent patients had autoimmune diseases, and one had IBD that required neither corticosteroids nor immunosuppressive therapy.

\section{Comparison of characteristics between} immunocompetent and immunocompromised patients Comparison of age, gender, underlying diseases, clinical setting status, clinical presentations, laboratory tests, location involvement, endoscopic findings, treatment, and outcomes are shown in Table 1.

\section{Demographic characteristics and underlying diseases}

Patients in the immunocompetent group were significantly older than patients in the immunocompromised group (73.0 vs. 48.6 years, respectively; $p<0.01$ ). Fiftyfive percent of immunocompetent patients and $61.5 \%$ of immunocompromised patients were male $(p=0.44)$. Major metabolic comorbidities, such as diabetes and large vessel atherosclerosis, were significantly more prevalent in the immunocompetent group. The HbA1C level was available in 15 of 20 immunocompetent hosts and 17 of 21 immunocompromised hosts. The mean HbA1C level was $7.12 \% \pm 1.51 \%$ in the immunocompetent and $7.13 \% \pm 1.45 \%$ in the immunocompromised group ( $p=0.977)$. The prevalence of chronic kidney disease was 23.2 and $23.9 \%$ in the immunocompetent and the immunocompromised group, respectively. The prevalence and stage of chronic kidney disease were not different between the two groups. The prevalence of cirrhosis was 3.6 and $3.4 \%$ in the immunocompetent and the immunocompromised group, respectively. The prevalence and Child-Pugh classification of cirrhosis were also not different between the two groups.

\section{Clinical setting status}

The diagnosis of CMV was made during admission in the intensive care unit (ICU) more frequently in the immunocompetent group (12 patients, 21.4\%) than in the immunocompromised group (10 patients, 8.6\%). Furthermore, the medical conditions at the time of diagnosis appeared to be worse in the immunocompetent group since the rates of respiratory failure ( $35.7 \%$ vs. $21.4 \%, p=0.04)$, use of inotropic drugs $(33.9 \%$ vs. $8.6 \%, p<0.01)$, and renal failure $(39.3 \%$ vs. $22.2 \%, p=0.02$ ) were significantly higher than in the immunocompromised group.

When defined critical illness by requiring either mechanical ventilator or inotropic agents, 25 immunocompetent and 25 immunocompromised patients were included. Of these patients, GI-CMV was the primary disease in only three immunocompetent (12\%) and five immunocompromised patients (20\%). The causes of severe illnesses in immunocompetent patients were severe infections or sepsis in 13 patients (52\%), malignancy-associated conditions such as undergoing surgery for tumor resection in 3 patients (12\%), cardiovascular diseases in 3 patients (12\%), and other conditions in 3 patients. For immunocompromised patients, severe infections or sepsis was noted in 8 patients (32\%), malignancy-associated conditions, or receiving chemotherapy in 6 patients (24\%), HIV-related diseases in 2 patients (8\%), and other conditions in 4 patients.

\section{Clinical presentations}

The immunocompetent patients had more acute presenting symptoms than those presented by immunocompetent patients. The median duration of presenting symptoms in the immunocompetent group was 1 day (range: 1-60), which was significantly less than the 10day (range: 1-210) duration in the immunocompromised group $(p<0.01)$. Moreover, the presenting symptoms were different between groups. Immunocompetent patients were significantly more likely to present with GI bleeding ( $71.4 \%$ vs. $38.5 \% ; p<0.01$ ); whereas, diarrhea and abdominal pain were more common in the immunocompromised group. Eight (6.8\%) immunocompromised patients had concomitant extra-gastrointestinal CMV infections, including six patients with retinitis, one patient with radiculomyelitis, and one patient with retinitis and encephalitis. There was no concurrent extra-gastrointestinal CMV infection in the immunocompetent group.

\section{Blood CMV viral load}

Blood CMV viral load was obtained in 112 cases - 27 immunocompetent and 85 immunocompromised patients. The median viral load in immunocompetent patients and immunocompromised patients was 370 and 2736 copies $/ \mathrm{mL}$, respectively $(p=0.01)$. Forty percent of immunocompetent patients and 13\% of immunocompromised patients had undetectable viral load $(p<0.01)$. 
Table 1 Characteristics of patients with gastrointestinal cytomegaloviral infection

\begin{tabular}{|c|c|c|c|}
\hline & Immunocompetent $(n=56)$ & Immunocompromised $(n=117)$ & $P$ \\
\hline Age, year (mean $\pm S D)$ & $73.0 \pm 13.9$ & $48.6 \pm 16.4$ & $<.0001$ \\
\hline Male gender & $31(55.4 \%)$ & $72(61.5 \%)$ & 0.44 \\
\hline \multicolumn{4}{|l|}{ Immunocompromised conditions } \\
\hline HIV infection & 0 & \multicolumn{2}{|l|}{$34(29.1 \%)$ CD4 (median 19, 1-187) } \\
\hline Transplantation & 0 & \multicolumn{2}{|l|}{$24(20.5 \%)$} \\
\hline Cancers receiving chemotherapy & 0 & \multicolumn{2}{|l|}{$21(17.9 \%)$} \\
\hline Autoimmune diseases & 2 (3.6\%) (not receive steroid, immunosuppressant) & \multicolumn{2}{|l|}{$30(25.6 \%)$} \\
\hline Inflammatory bowel diseases $(C D=3, \cup C=8)$ & $1(1.8 \%)$ (not receive steroid, immunosuppressant) & \multicolumn{2}{|l|}{$10(8.6 \%)$} \\
\hline Other conditions requiring corticosteroids & & \multicolumn{2}{|l|}{$8(6.8 \%)$} \\
\hline \multicolumn{4}{|l|}{${ }^{a} 10$ patients had two underlying conditions } \\
\hline \multicolumn{4}{|l|}{ Medications } \\
\hline Corticosteroids & 0 & \multicolumn{2}{|l|}{$70(40.5 \%)$} \\
\hline Chemotherapy & 0 & \multicolumn{2}{|l|}{$21(18.0 \%)$} \\
\hline Immunosuppressive agents & 0 & \multicolumn{2}{|l|}{$44(37.6 \%)$} \\
\hline \multicolumn{4}{|l|}{ Underlying diseases } \\
\hline Diabetes mellitus & $20(35.7 \%)$ & $21(18.0 \%)$ & 0.010 \\
\hline Large vessel atherosclerotic diseases & $21(37.5 \%)$ & $14(12.0 \%)$ & $<0.0001$ \\
\hline Chronic kidney disease & $13(23.2 \%)$ & $28(23.9 \%)$ & 0.917 \\
\hline $\begin{array}{l}\text { - Stage } 3 \\
\text { - Stage } 4 \\
\text { - Stage } 5\end{array}$ & $\begin{array}{l}6(46.2 \%) \\
1(7.6 \%) \\
6(46.2 \%)\end{array}$ & $\begin{array}{l}6(21.4 \%) \\
5(17.9 \%) \\
17(60.7 \%)\end{array}$ & 0.244 \\
\hline Cirrhosis & $2(3.6 \%)$ & $4(3.4 \%)$ & $>.99$ \\
\hline $\begin{array}{l}\text { - Child-Pugh A } \\
\text { - Child-Pugh B } \\
\text { - Child-Pugh C }\end{array}$ & $\begin{array}{l}0(0 \%) \\
1(50 \%) \\
1(50 \%)\end{array}$ & $\begin{array}{l}1(25 \%) \\
3(75 \%) \\
0(0 \%)\end{array}$ & 0.269 \\
\hline \multicolumn{4}{|l|}{ Status conditions at diagnosis } \\
\hline Clinical Setting & & & 0.024 \\
\hline $\begin{array}{l}\text { - Outpatient } \\
\text { - Inpatient } \\
\text { - Intensive care }\end{array}$ & $\begin{array}{l}23(41.1 \%) \\
21(37.5 \%) \\
12(21.4 \%)\end{array}$ & $\begin{array}{l}69(59.0 \%) \\
38(32.5 \%) \\
10(8.6 \%)\end{array}$ & \\
\hline Bacteremia & $4(7.1 \%)$ & $11(9.4 \%)$ & 0.776 \\
\hline Systemic inflammatory response syndrome & $29(52.7 \%)$ & $53(45.7 \%)$ & 0.39 \\
\hline Respiratory failure & $20(35.7 \%)$ & $25(21.4 \%)$ & 0.04 \\
\hline Inotropic drugs & 19 (33.9\%) & $10(8.6 \%)$ & $<.0001$ \\
\hline Acute renal failure & $22(39.3 \%)$ & $26(22.2 \%)$ & 0.02 \\
\hline \multicolumn{4}{|l|}{ Presentation } \\
\hline Median presenting duration, days (range) & $1(1-60)$ & $10(1-210)$ & 0.0015 \\
\hline Gl bleeding & $40(71.4 \%)$ & $45(38.5 \%)$ & $<.0001$ \\
\hline Diarrhea & $18(32.1 \%)$ & $63(53.8 \%)$ & 0.007 \\
\hline Abdominal pain & 9 (16.1\%) & 39 (33.3\%) & 0.018 \\
\hline Fever & $27(49.1 \%)$ & 66 (56.4\%) & 0.369 \\
\hline Severe ileus & $4(7.1 \%)$ & $3(2.6 \%)$ & 0.215 \\
\hline Perforation & $1(1.8 \%)$ & $3(2.6 \%)$ & $>.99$ \\
\hline CMV at other organs & $0(0 \%)$ & $8(6.8 \%)$ & 0.055 \\
\hline
\end{tabular}

Investigations 
Table 1 Characteristics of patients with gastrointestinal cytomegaloviral infection (Continued)

\begin{tabular}{|c|c|c|c|}
\hline & Immunocompetent $(n=56)$ & Immunocompromised $(n=117)$ & $P$ \\
\hline \multicolumn{4}{|l|}{ CMV viral load $(n=112)$} \\
\hline - Median (range, IQR) & $370(0-85,599,4951)$ & $2736(0-2,988,940,27,074)$ & 0.010 \\
\hline - $C M V V L=0$ & $11 / 27(40.7 \%)$ & $11 / 85(12.9 \%)$ & 0.002 \\
\hline \multicolumn{4}{|l|}{ Location involvement } \\
\hline Esophagus & $4(7.1 \%)$ & $14(12.0 \%)$ & 0.430 \\
\hline Stomach & $10(17.9 \%)$ & $32(27.4 \%)$ & 0.173 \\
\hline Duodenum & $1(1.8 \%)$ & $11(9.4 \%)$ & 0.106 \\
\hline Jejunum & $1(1.8 \%)$ & $4(3.4 \%)$ & $>.999$ \\
\hline lleum & $13(23.2 \%)$ & $27(23.1 \%)$ & 0.984 \\
\hline Colon (rectum not included) & $33(58.9 \%)$ & 70 (59.8\%) & 0.910 \\
\hline Rectum & $14(25.0 \%)$ & $31(26.5 \%)$ & 0.834 \\
\hline \multicolumn{4}{|l|}{ Endoscopic findings } \\
\hline EGD & $N=14$ & $N=45$ & \\
\hline Ulcer & $13(92.9 \%)$ & 37 (82.2\%) & 0.671 \\
\hline Inflammatory mucosa & $6(42.9 \%)$ & $25(55.6 \%)$ & 0.406 \\
\hline Mass & $2(14.3 \%)$ & $0(0 \%)$ & 0.053 \\
\hline Colonoscopy & $N=40$ & $N=80$ & \\
\hline Ulcer & $33(82.5 \%)$ & $55(68.8 \%)$ & 0.108 \\
\hline Inflammatory mucosa & $26(65.0 \%)$ & $53(66.3 \%)$ & 0.892 \\
\hline Mass & $4(10 \%)$ & $4(5.0 \%)$ & 0.301 \\
\hline Balloon-assisted enteroscopy & $N=1$ & $N=2$ & \\
\hline Ulcer & $1(100 \%)$ & $2(100 \%)$ & \\
\hline Inflammatory mucosa & $1(100 \%)$ & $2(100 \%)$ & \\
\hline Mass & $0(0 \%)$ & $0(0 \%)$ & \\
\hline \multicolumn{4}{|l|}{ Treatment and outcomes } \\
\hline \multicolumn{4}{|l|}{ Medications } \\
\hline - Ganciclovir & $36 / 51(70.6 \%)$ & 105/114 (92.1\%) & 0.0003 \\
\hline - Valganclovir & $3 / 51(5.9 \%)$ & $15 / 114(13.2 \%)$ & 0.278 \\
\hline - Surgery & $6 / 51(11.8 \%)$ & 9/114 (7.9\%) & 0.424 \\
\hline • None & $13 / 51(25.5 \%)$ & $5 / 114(4.4 \%)$ & $<.0001$ \\
\hline Median duration of treatment, week (range) & $3(0-6)$ & $3(0-28)$ & 0.003 \\
\hline Death in 6 months & & & $0.047^{* *}$ \\
\hline • in 1 month & $11 / 51(21.6 \%)$ & $16 / 114(14.0 \%)$ & \\
\hline - in 6 months & 20/51 (39.2\%) & $25 / 114(21.9 \%)$ & \\
\hline \multicolumn{4}{|l|}{ Mucosal healing ${ }^{c}$} \\
\hline - in 6 weeks & $6 / 9(66.7 \%)$ & $7 / 20(35 \%)$ & 0.226 \\
\hline - at or after 6 weeks & 8/9 (88.9\%) & 16/19 (67.9\%) & $>0.99$ \\
\hline
\end{tabular}

${ }^{a}$ Ten patients had two underlying condition including 4 with glomerulonephritis undergoing renal transplantation, 3 with hematologic malignancies undergoing bone marrow transplantation, one with HIV and ITP, one with ulcerative colitis and autoimmune hemolytic anemia, and one with malignant thymoma and myasthenia gravis

blog-rank test

'only the patients who did not have underlying gastrointestinal disease

\section{Location of involvement and endoscopic findings}

In this cohort, CMV infection involved lower GI tract more frequently than upper GI tract in both groups. The immunocompromised group tended to have CMV gastritis more frequently than the immunocompetent group, but the difference between groups was not statistically significant. For endoscopic evaluation, 169 patients had lesions identified during endoscopy, and the 
tissue biopsies were positive for CMV. Of these, 46 patients had lesions detected by EGD, 107 by colonoscopy, 13 by both EGD and colonoscopy, and three by enteroscopy. The remaining four patients, who did not have endoscopic findings, were diagnosed based on surgical specimens, including one colonic perforation undergoing right hemicolectomy, one colonic obstruction undergoing subtotal colectomy, and two massive ileal bleeding with failed angioembolization undergoing ileal resection. There was no significant difference between groups relative to the finding of endoscopic lesion. Ulcer was the most common type of lesion, with a prevalence of approximately $80-90 \%$ in both groups. The ulcers could be either small or large, and they frequently had a clean base (Fig. 1a). Some ulcers had a picture resembling the single stripe sign, which is generally seen in ischemic colitis (Fig. 1b). The intervening mucosa ranged from normal to severely inflamed (Fig. 1c).

\section{Treatment}

Five immunocompetent and 3 immunocompromised patients were referred, which left 51 immunocompetent and 114 immunocompromised patients with available follow-up data. About $70 \%$ of immunocompetent patients received antiviral agents. This proportion was significantly less than the proportion in the immunocompromised group, which had a rate of $92 \%(p<0.01)$. Ganciclovir was given first to most patients who received antiviral agents, and some patients were switched to valganciclovir. Only 3 patients were started on valganciclovir. More patients in the immunocompetent group (15.7\%) required surgery than patients in the immunocompromised group (7.9\%) $(p=0.13)$. The proportion of patients who did not receive any specific treatment for CMV infection was significantly higher among immunocompetent patients than among immunocompromised patients $(25.5 \%$ vs. $4.4 \%, p<0.01)$.

\section{Mortality rate and predictive factors}

At the 6-month follow-up time point, 20 (39.2\%) immunocompetent and 25 (21.9\%) immunocompromised patients had died, and more than half of those patients died within one month. As shown in Fig. 2, the all-cause mortality rate was significantly higher in immunocompetent group $(p=0.047)$.

Multivariate analysis that included age, gender, clinical setting status, presence of systemic inflammatory response syndrome, presence of respiratory failure, presence of acute renal failure, requirement for inotropic drugs, immune status, and receiving antiviral agents, revealed old age, inpatient status, and ICU setting at diagnosis to be independent predictors of 6-month mortality. Treatment with antiviral agents was the only independent protective factor against 6-month mortality, as shown in Table 2.

\section{Improvement in endoscopic findings}

Seventy-seven patients underwent follow-up endoscopy. Of those, 20 patients had underlying gastrointestinal
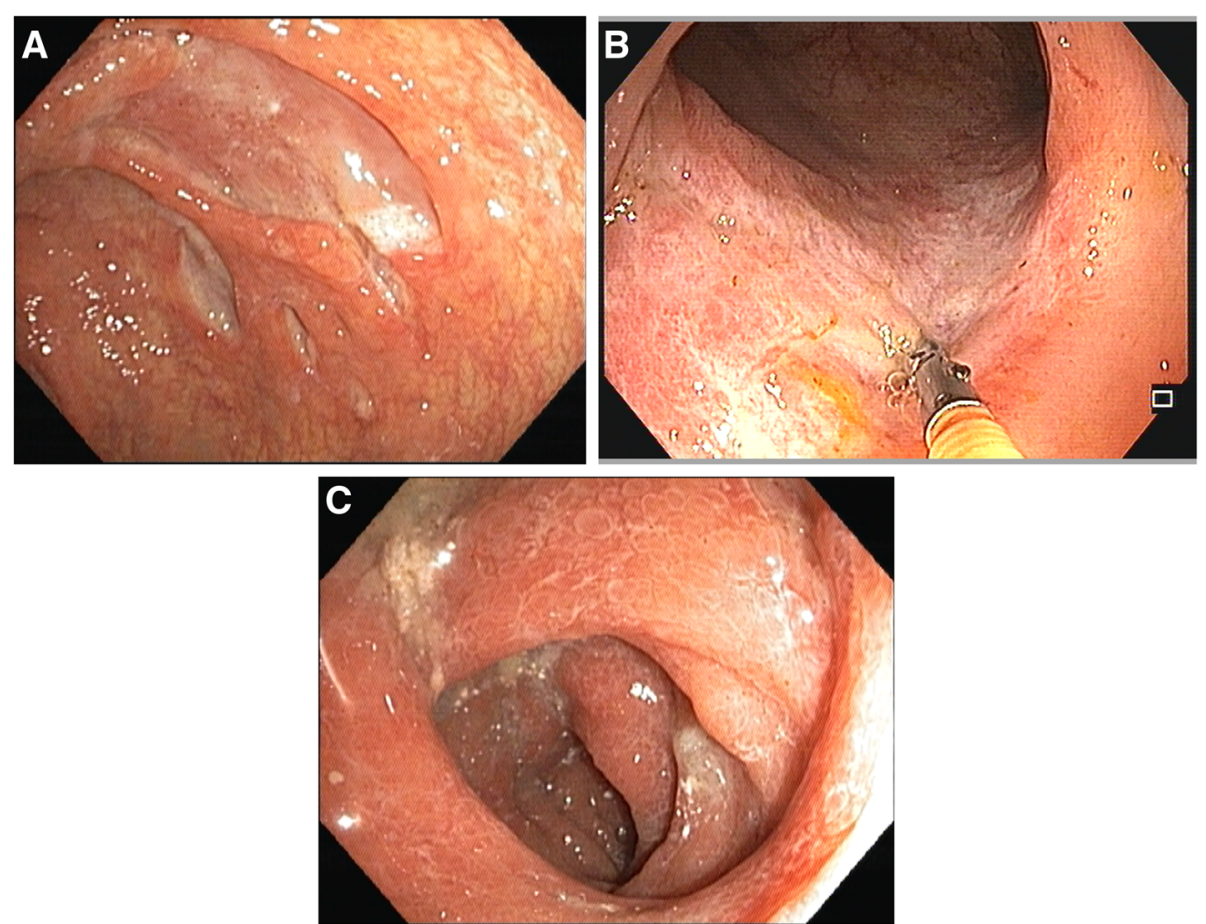

Fig. 1 Endoscopic pictures. 1A) Large clean-base ulcers. 1B) Single longitudinal ulcer at sigmoid colon resembling the single stripe sign in ischemic colitis. 1C) Severely inflamed mucosa 


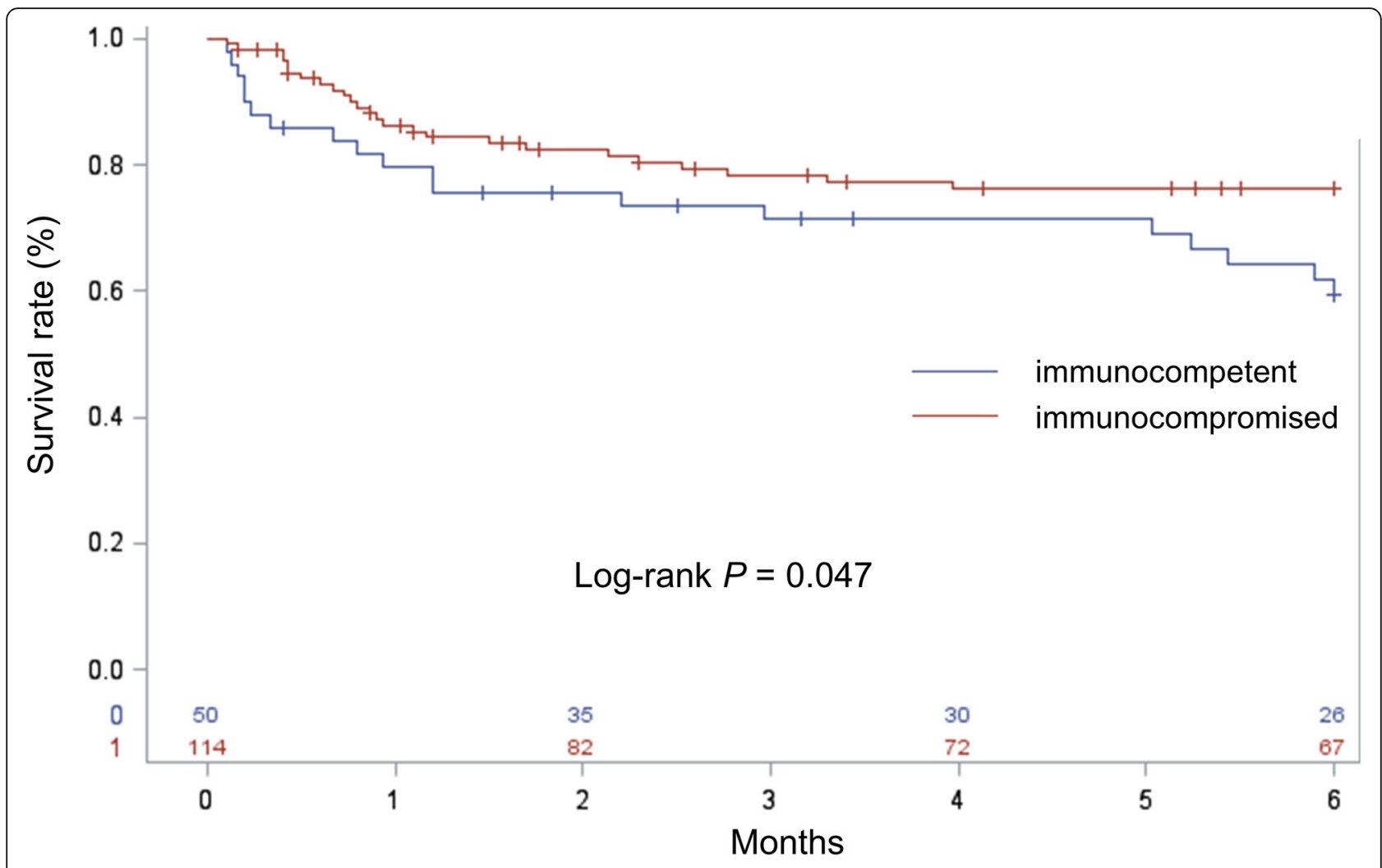

Fig. 2 Six-month mortality compared between immunocompetent and immunocompromised gastrointestinal cytomegalovirus infection patients

diseases and were not evaluated for mucosal healing. Among the remaining 57 patients who did not have underlying gastrointestinal diseases, the median time of follow-up endoscopy was 6 weeks (range: 1.3-77.3). Among the 29 patients who had endoscopic follow-up before 6 weeks, complete healing was observed in 6 of 9 (67\%) immunocompetent patients, and in 7 of 20 (35\%) immunocompromised patients $(p=0.23)$. Among the 28 patients who had endoscopic follow-up at or after 6 weeks, complete healing was seen in 8 of $9(89 \%)$ immunocompetent patients, and in 16 of $19(84 \%)$ immunocompromised patients $(p>0.99)$.

\section{Recurrence of disease}

At a median follow-up of 13 months (range: 0.1-111), 7 patients developed recurrent GI-CMV infection. Of those,

Table 2 Multivariate analysis for predicting 6 month-mortality

\begin{tabular}{llll}
\hline Variables & Hazard ratio & $95 \%$ confident interval & $p$-value \\
\hline Age & 1.021 & $1.002-1.040$ & 0.03 \\
Status & & & \\
• Outpatients & 1 (reference) & & \\
- Inpatients & 4.31 & $1.95-9.55$ & $<.01$ \\
- ICU & 9.14 & $3.67-22.76$ & $<.01$ \\
Antiviral agents & 0.24 & $0.11-0.51$ & $<.01$ \\
\hline
\end{tabular}

5 were immunocompromised patients; 2 had ulcerative colitis that required corticosteroids and immunomodulators; 1 had myasthenia gravis requiring corticosteroids; 1 had myeloid sarcoma that was being treated with allogenic stem cell transplantation; and, 1 patient had AIDS and a CD4 count of $1 \mathrm{cell} / \mathrm{mm}^{3}$. One patient in the immunocompetent group developed recurrent GI-CMV infection after receiving corticosteroids for one month for treatment of Crohn's disease that developed after CMV infection. Another patient in the immunocompetent group suffered from cerebrovascular disease and was bedridden. He developed recurrent GI-CMV infection while stricken with nosocomial sepsis. The median time to recurrence was 4 months (range: $2.3-26.0$ ). The details of these cases are shown in Table 3.

\section{Literature review}

The PubMed search using the terms described in the Methods section yielded 181 articles. Our abstract review identified 68 articles that were either case reports or case series of GI-CMV disease in immunocompetent hosts. Of those, 6 case series with at least 10 cases were selected to be reviewed and summarized (Table 4) [7, 14-16, 27, 28]. 
Table 3 Recurrent cases

\begin{tabular}{|c|c|c|c|c|}
\hline & Underlying disease & Treatment & $\begin{array}{l}\text { Follow up } \\
\text { endoscopy }\end{array}$ & $\begin{array}{l}\text { Time of } \\
\text { recurrence }\end{array}$ \\
\hline 1 & Acute myeloid leukemia s/p allogenic stem cell transplantation with graft-versus-host disease & $\begin{array}{l}\text { Ganciclovir } 3 \\
\text { weeks }\end{array}$ & FU at 3 weeks & 2.3 months \\
\hline 2 & DM, coronary artery disease, cerebrovascular disease, atrial fibrillation with infected bed sore & $\begin{array}{l}\text { Ganciclovir } 6 \\
\text { weeks }\end{array}$ & FU at 5 weeks & 2.6 months \\
\hline 3 & AIDS, CD4 count $=1$ at the diagnosis & $\begin{array}{l}\text { Ganciclovir } 6 \\
\text { weeks }\end{array}$ & No & 4 months \\
\hline 4 & Myasthenia gravis on corticorsteroid, immunosuppressive agents & $\begin{array}{l}\text { Ganciclovir } 3 \\
\text { weeks }\end{array}$ & No & 20 months \\
\hline 5 & Ulcerative colitis with steroid dependent & $\begin{array}{l}\text { Ganciclovir } 3 \\
\text { weeks }\end{array}$ & FU at 11 weeks & 26 months \\
\hline 6 & $\begin{array}{l}\text { Pregnancy with colitis with first diagnosis of CMV and Crohn's disease. Recurrence occurred after } \\
\text { started prednisolone for a month }\end{array}$ & $\begin{array}{l}\text { Ganciclovir } 3 \\
\text { weeks }\end{array}$ & FU at 4 weeks & 3.5 months \\
\hline 7 & Ulcerative colitis with steroid dependent & $\begin{array}{l}\text { Ganciclovir } 2 \\
\text { weeks }\end{array}$ & FU at 11 weeks & 23.8 months \\
\hline
\end{tabular}

\section{Discussion}

This retrospective review of 173 patients diagnosed with GI-CMV during the last ten years at our center revealed that CMV gastrointestinal disease in immunocompetent patients is not rare. In fact, about one-third of GI-CMV infection patients in our hospital did not have obvious immunocompromised status. Furthermore, immunocompetent GI-CMV infection patients were significantly older, had more major metabolic comorbidities, had more severe clinical setting, and commonly presented with gastrointestinal bleeding. CMV viremia was quite uncommon in immunocompetent patients when compared to immunocompromised patients. The mortality rate at 6 months was higher in immunocompetent patients; however, this may be attributable to the significantly older age of immunocompetent patients, and the fact that they had more severe underlying disease.

Like other herpes viruses, CMV causes a primary infection that is followed by a latent infection. Viral DNA has been detected in monocytes, dendritic cells, megakaryocytes, and myeloid progenitor cells in bone marrow [32]. Reactivation causing tissue-invasive diseases usually occur in immunocompromised patients, including those with AIDS, organ transplantation, and those receiving immunosuppressive agents. However, CMV has been reported to cause severe infection in immunocompetent patients, and the GI tract was the most frequent site of infection [33]. Our study showed that the prevalence of GI-CMV infection is not rare since about one-third of GI-CMV patients in our cohort did not have apparent immunocompromised status. This prevalence is similar to that from a previous report by Patra, et al. [1]

To comprehensively identify and describe the disease characteristics, we performed a literature review and obtained details and data from cohorts with at least 10 cases, as summarized in Table 4.
Regarding risk factors, immunocompetent individuals who had GI-CMV infection in our cohort had some conditions that could compromise their immune function. Advanced age is one of the most important risk factors. The immunocompetent patients in our cohort had a mean age of 73 years, which is comparable to the mean age of patients in other cohorts [7, 14-16, 27, 28]. Some underlying diseases may be associated with CMV reactivation. We found that about one-third of our immunocompetent patients had diabetes mellitus (DM) or large vessel atherosclerosis disease, both of which were found to be significantly higher than in the immunocompromised group. A significant proportion of immunocompetent patients in other cohorts were also reported to have these conditions [7, 16, 27, 28, 31]. Chronic kidney disease was found in about $23 \%$ of our immunocompetent patients. Although this prevalence was not significantly different between groups in our study, chronic kidney disease was also found to be quite common in other cohorts, with a prevalence ranging from 14 to $50 \%[7,14,16,27,28,31]$. Uremia and dialysis may cause dysfunction of B-cell and T-cell lymphocytes, impaired cytokine regulation, and perturbation of mucosal immunity [34]. Interestingly, cirrhosis does not seem to be a risk factor for development of GI-CMV disease. The prevalence of cirrhosis among GI-CMV was reported to range from 0 to $5.9 \%[7,16,27,28,31]$. Severe critical illness can cause immune paralysis that was reported to be associated with CMV reactivation [35]. Many studies, including ours, found and reported that $20-100 \%$ of patients were in an ICU setting [7, 16, 27].

The clinical manifestations of GI-CMV disease in immunocompetent and immunocompromised patients appear to be different. In our study and in other cohorts, the majority of immunocompetent patients presented with gastrointestinal bleeding $[7,16,27,28]$, while 
Table 4 Summary of the cohorts of gastrointestinal cytomegaloviral infection in immunocompetent patients (only the cohort with at least 10 patients)

\begin{tabular}{|c|c|c|c|c|c|c|c|}
\hline & $\begin{array}{l}\text { Ng } 1999(n= \\
\text { 10, colitis) }\end{array}$ & $\begin{array}{l}\text { Maiorana, } \\
2003(n=11)\end{array}$ & $\begin{array}{l}\text { Siciliano, } 2014 \\
(n=14, I C U)\end{array}$ & $\begin{array}{l}\text { Bernard, S } \\
2015(n=13)\end{array}$ & $\begin{array}{l}\text { Ko, } 2015(n= \\
51, \text { colitis) }\end{array}$ & $\begin{array}{l}\text { Le } 2017 \text { ( } n=42 \text {, } \\
\text { colitis) }\end{array}$ & $\begin{array}{l}\text { Current study } \\
(n=56)\end{array}$ \\
\hline Age & 71 & 72 & 64.2 & $81(54-88)$ & $65.2 \pm 14.0$ & $64.4 \pm 19.4$ & $73.0 \pm 13.9$ \\
\hline Male gender & $1(10 \%)$ & $9(88 \%)$ & $6(42.8 \%)$ & $5(38 \%)$ & $24(47.1 \%)$ & $24(57.1 \%)$ & $31(55.4 \%)$ \\
\hline \multicolumn{8}{|l|}{ Underlying disease } \\
\hline Diabetes mellitus & $2(20 \%)$ & & $5(35.7 \%)$ & $3(23.1 \%)$ & 15 (29.4\%) & 15 (35.7\%) & $20(35.7 \%)$ \\
\hline $\begin{array}{l}\text { Large vessel } \\
\text { atherosclerotic diseases }\end{array}$ & $2(20 \%)$ & & & & $\begin{array}{l}11 \text { (21.6\%) } \\
\text { (CVS dis) }\end{array}$ & $\begin{array}{l}8 \text { (19) CAD } 8 \text { (19) } \\
\text { CVA }\end{array}$ & $21(37.5 \%)$ \\
\hline Chronic kidney disease & $2(20 \%)$ & & $7(50 \%)$ & $2(15.4 \%)$ & $16(31.4 \%)$ & $6(14.3 \%)$ & $13(23.2 \%)$ \\
\hline Cirrhosis & 0 & & 0 & 0 & $3(5.9 \%)$ & $2(4.8 \%)$ & $2(3.6 \%)$ \\
\hline Cardiomyopathy & & & $9(64.2 \%)$ & & & & \\
\hline
\end{tabular}

Status conditions at diagnosis

Status

- Outpatient

- Inpatient

- Intensive care unit

$100 \%$

Bacteremia

SIRS

Respiratory failure

$71.4 \%$

Inotropic drugs

$78.5 \%$

$\begin{array}{lll} & 5(11.9 \%) & 23(41.1 \%) \\ 11(21.6 \%) & 21(50 \%) & 21(37.5 \%) \\ & 8(19 \%) & 12(21.4 \%) \\ 28(66.7 \%) & 4(7.1 \%) \\ 15(35.7 \%) & 29(52.7 \%) \\ 13(31 \%) & 19(33.9 \%) \\ 14(33.3 \%) & 22(39.3 \%)\end{array}$

Presentation

$\begin{array}{ll}\begin{array}{l}\text { Median presenting } \\ \text { duration (days) (range) }\end{array} & \\ \text { Gl bleeding } & 9(90 \%) \\ \text { Diarrhea } & 8(80 \%) \\ \text { Abdominal pain } & 0 \\ \text { Fever } & 6(60 \%) \\ \text { lleus } & \\ \text { Perforation } & 0 \\ \text { CMV at other organs } & 0\end{array}$

$8(1-30)$

$1(1-60)$

$10(71.4 \%)$
$6(42.8 \%)$
$1(7.1 \%)$
$2(14.3 \%)$
$1(7.1 \%)$
0
0

$$
\begin{aligned}
& 6(46.2 \%) \\
& 6(46.2 \%) \\
& 0 \\
& 4(30.8 \%) \\
& 0 \\
& 0
\end{aligned}
$$$$
30(58.8 \%)
$$$$
22(52.4 \%)
$$$$
40(71.4 \%)
$$$$
23(45.1 \%)
$$$$
15(35.7 \%)
$$$$
18(32.1 \%)
$$$$
8(15.7 \%)
$$$$
12(28.6 \%)
$$$$
9(16.1 \%)
$$$$
8(15.7 \%)
$$$$
17(40.5 \%)
$$$$
27(49.1 \%)
$$

MV viremia

0

0

CMV viral
load $(n=4)$

Antigenemia

$(n=30)$

Median,

range

$2(0-11)$

Negative Negative

3/4 (75\%) $13(43 \%)$

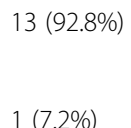

$4(30.8 \%)$
$6(46.2 \%)$

$39(76.5 \%)$

$24(57.1 \%)$

$36 / 51(70.6 \%)$

$3(30 \%)$

- Valganclovir

$1(10 \%)$

$1(7.2 \%)$
0

$5(9.8 \%)$
- Surgery

$12(28.6 \%)$

$3 / 51(5.9 \%)$

$8 / 51(15.7 \%)$
$4(7.1 \%)$

$1(1.8 \%)$

$0(0 \%)$ 
Table 4 Summary of the cohorts of gastrointestinal cytomegaloviral infection in immunocompetent patients (only the cohort with at least 10 patients) (Continued)

\begin{tabular}{|c|c|c|c|c|c|c|c|}
\hline & $\begin{array}{l}\operatorname{Ng} 1999(n= \\
10, \text { colitis) }\end{array}$ & $\begin{array}{l}\text { Maiorana, } \\
2003(n=11)\end{array}$ & $\begin{array}{l}\text { Siciliano, } 2014 \\
(n=14, \text { ICU) }\end{array}$ & $\begin{array}{l}\text { Bernard, S } \\
2015(n=13)\end{array}$ & $\begin{array}{l}\text { Ko, } 2015(n= \\
\text { 51, colitis) }\end{array}$ & $\begin{array}{l}\text { Le } 2017 \text { ( } n=42 \text {, } \\
\text { colitis) }\end{array}$ & $\begin{array}{l}\text { Current study } \\
(n=56)\end{array}$ \\
\hline - None & $7(70 \%)$ & & & $7(53.8 \%)$ & & $12(28.6 \%)$ & $13 / 51(25.5 \%)$ \\
\hline $\begin{array}{l}\text { Duration of } \\
\text { treatment (week) }\end{array}$ & & & & 3 & 2 & 3 & $3(0-6)$ \\
\hline $\begin{array}{l}\text { Improvement with } \\
\text { no treatment }\end{array}$ & $7(70 \%)$ & & & & $9(17.6 \%)$ & & $4(7.1 \%)$ \\
\hline Death in 6 months & & & $\begin{array}{l}10(71.4 \%) \text { (in } \\
\text { hospital mortality) }\end{array}$ & $\begin{array}{l}\text { no CMV- } \\
\text { related death }\end{array}$ & 7.8\% (30 days) & $\begin{array}{l}11(26.2 \%) \text { (in } \\
\text { hospital mortality) }\end{array}$ & 20/51 (39.2\%) \\
\hline
\end{tabular}

diarrhea was the most common presentation in immunocompromised patients [7]. It is known that CMV can infect vascular endothelium resulting in ischemic damage to the mucosa that causes bleeding [36]. In immunocompetent patients, the ischemic process may be potentiated by hypoperfusion state caused by underlying conditions, and this may cause more bleeding. The endoscopic finding of the "single-stripe sign", which is normally observed in patients with ischemic colitis, was found in some GI-CMV patients and supports this hypothesis (Fig. 1b). Concomitant CMV infection in other organs is extremely rare. Neither our study nor any of the other previous case series found any cases of concomitant CMV infection in other organs [7, 14, 16, 27, 28]. In contrast, concomitant CMV infection in other organs was reported in $7 \%$ of immunocompromised patients. This suggests a hypothesis that CMV reactivation in immunocompetent host is a local reactivation rather than a systemic reactivation. This hypothesis could be supported by the results of blood tests for viremia since as high as 40$75 \%$ of patients had negative test for viremia, either by $\mathrm{Ag}$ detection or by CMV viral load [7, 27, 28].

The role of specific antiviral treatment for immunocompetent patients is still being debated. A 2005 systematic review showed that spontaneous resolution occurred mainly in patients $<55$ years of age that had no other comorbidities [31]. Treatment with antiviral agents was reported to have no effect on mortality rate [7]. However, interestingly, and in contrast - treatment with antiviral agents was identified as the only significant protective factor against death in our study. This issue needs to be further investigated in randomized controlled study.

The reported mortality rate ranged from 8 to $71.4 \%[7,14$, $16,27,31]$. The differences in mortality among groups is likely explained by differences in patient characteristics. The mortality rate in our cohort at 6 months after diagnosis in immunocompetent patients was $39 \%$, which is significantly higher than the rate in immunocompromised host. However, immune status was not found to be a significant factor in multivariate analysis. The main risk factors for death were old age, inpatient status, and ICU admission at diagnosis.

Mucosal healing was observed in only about half of patients who had endoscopic follow-up before 6 weeks; however, mucosal healing was found in $90 \%$ of those who underwent endoscopic follow-up at or later than 6 weeks, with no significant difference observed between the immunocompetent and immunocompromised groups. This suggests that follow-up endoscopy should not be performed too early.

Recurrence was observed in only $5 \%$ of patients in this cohort. Six of 7 patients had compromised immune status at the time of disease recurrence. This low rate of disease recurrence may be attributed to recovery of patient immune function after recovery from severe illness, or as a result of treatment with anti-retroviral agents in AIDS patients. These findings suggest that recurrence of CMV infection is most likely to occur in immunocompromised patients, and particularly among those with poor immune function.

The strength of this study is that it is the largest study in GI-CMV in immunocompetent patients. Furthermore, we included all GI-CMV infection patients that were diagnosed at our center during the last 10 years, and this allowed us to determine the relative incidence of GI-CMV compared between immunocompetent and immunocompromised patients. We comprehensively reported clinical manifestations, investigations, clinical progression including relapse rate. We also performed a literature review that permitted us to compare our findings with those from every study that included ten or more patients. Our study also has some limitations. First, the retrospective nature of our study rendered it vulnerable to missing or incomplete data, such as CMV viral load data was not available for all patients. Second, our data was derived from a single center, so our findings may not be generalizable to other centers or healthcare settings. Third and last, patient management was based on the judgment of the treating physicians, so conclusions specific to the effects of treatment could not be drawn.

\section{Conclusion}

GI-CMV infection was frequently observed among immunocompetent elderly patients with comorbidities or severe concomitant illnesses. GI bleeding was the most common presentation. Blood CMV viral load was not diagnostically helpful. Significantly higher mortality was 
observed in immunocompetent patients than in immunocompromised patients, but this could be due to more severe concomitant illnesses in the immunocompetent group. Anti-viral agents had a positive effect in this study, and could help to decrease the mortality rate in immunocompromised patients, but need further studies.

\section{Abbreviations}

CMV: Cytomegalovirus; Gl: Gastrointestinal; IBD: Inflammatory bowel disease; ICU: Intensive care unit

\section{Acknowledgements}

The authors gratefully acknowledge Kevin Jones for language editing.

\section{Authors' contributions}

Planning and conducting the study: JL. Collecting data: TC, AS, AP, JL. Literature review: $C T$, JL. Interpreting data: JL. Drafting the manuscript: $C T$, JL. Critical revision of the manuscript and intellectual content: JL, PC, NP, AP. All authors read and approved the final Manuscript.

\section{Funding}

This was an unfunded study.

\section{Availability of data and materials}

The datasets used and/or analysed during the current study are available from the corresponding author on reasonable request.

\section{Ethics approval and consent to participate}

The protocol for this study was approved by the Siriraj Institutional Review Board (SiRB) on 7 September 2018 (COA no. 566/2561). The requirement to obtain written informed consent from included patients was waived due to the anonymous retrospective nature of this study.

\section{Consent for publication}

Not applicable.

\section{Competing interests}

All authors declare that they have no competing interests.

\section{Author details}

'Division of Gastroenterology, Department of Medicine, Faculty of Medicine Siriraj Hospital, Mahidol University, Bangkok, Thailand. 'Department of Pathology, Faculty of Medicine Siriraj Hospital, Mahidol University, Bangkok, Thailand.

Received: 17 September 2019 Accepted: 19 January 2020 Published online: 30 January 2020

\section{References}

1. Patra S, Samal SC, Chacko A, Mathan V, Mathan MM. Cytomegalovirus infection of the human gastrointestinal tract. J Gastroenterol Hepatol. 1999;14(10):973-6.

2. Whitley RJ, Jacobson MA, Friedberg DN, Holland GN, Jabs DA, Dieterich DT, Hardy WD, Polis MA, Deutsch TA, Feinberg J, et al. Guidelines for the treatment of cytomegalovirus diseases in patients with AIDS in the era of potent antiretroviral therapy: recommendations of an international panel. International AIDS Society-USA. Arch Intern Med. 1998:158(9):957-69.

3. Baroco AL, Oldfield EC. Gastrointestinal cytomegalovirus disease in the immunocompromised patient. Curr Gastroenterol Rep. 2008;10(4):409-16.

4. Beswick L, Ye B, van Langenberg DR. Toward an algorithm for the diagnosis and management of CMV in patients with colitis. Inflamm Bowel Dis. 2016;22(12):2966-76.

5. O'Hara KM, Pontrelli G, Kunstel KL. An introduction to gastrointestinal tract CMV disease. JAAPA. 2017;30(10):48-52.

6. Harano $Y$, Kotajima L, Arioka H. Case of cytomegalovirus colitis in an immunocompetent patient: a rare cause of abdominal pain and diarrhea in the elderly. Int J Gen Med. 2015;8:97-100.

7. Le PH, Lin WR, Kuo CJ, Wu RC, Hsu JT, Su MY, Lin CJ, Chiu CT. Clinical characteristics of cytomegalovirus colitis: a 15-year experience from a tertiary reference center. Ther Clin Risk Manag. 2017;13:1585-93.
8. Hasegawa T, Aomatsu K, Nakamura M, Aomatsu N, Aomatsu K. Cytomegalovirus colitis followed by ischemic colitis in a non-immunocompromised adult: a case report. World J Gastroenterol. 2015;21(12):3750-4.

9. Naseem Z, Hendahewa R, Mustaev M, Premaratne G. Cytomegalovirus enteritis with ischemia in an immunocompetent patient: a rare case report. Int J Surg Case Rep. 2015;15:146-8.

10. Inayat F, Hussain Q, Shafique K, Tasleem SH, Hurairah A. Cytomegalovirus colitis in Immunocompetent patients. Cureus. 2016;8(11):e869.

11. Makker J, Bajantri B, Sakam S, Chilimuri S. Cytomegalovinus related fatal duodenal diverticular bleeding: case report and literature review. World J Gastroenterol. 2016;22(31):7166-74.

12. Gravito-Soares E, Gravito-Soares M, Camacho E, Tome L. Cytomegalovirus ulcerative oesophagitis in a young healthy immunocompetent patient. BMJ Case Rep. 2018;2018:1-5.

13. Yagel O, Israel S, Muszkat M, Ackerman Z, Szalat A. Challenges in the diagnosis of Cytomegalovirus colitis in a presumed Immunocompetent patient: interpretation of clinical condition, tissue, and serum Cytomegalovirus polymerase chain reaction findings. Isr Med Assoc J. 2018;20(3):194-6.

14. Ng FH, Chau TN, Cheung TC, Kng C, Wong SY, Ng WF, Lee KC, Chan E, Lai ST, Yuen WC, et al. Cytomegalovirus colitis in individuals without apparent cause of immunodeficiency. Dig Dis Sci. 1999;44(5):945-52.

15. Maiorana A, Baccarini P, Foroni M, Bellini N, Giusti F. Human cytomegalovirus infection of the gastrointestinal tract in apparently immunocompetent patients. Hum Pathol. 2003;34(12):1331-6.

16. Siciliano RF, Castelli JB, Randi BA, Vieira RD, Strabelli TM. Cytomegalovirus colitis in immunocompetent critically ill patients. Int J Infect Dis. 2014;20:71-3.

17. Surawicz CM, Myerson D. Self-limited cytomegalovirus colitis in immunocompetent individuals. Gastroenterology. 1988;94(1):194-9.

18. Blair SD, Forbes A, Parkins RA. CMV colitis in an immunocompetent adult. J R Soc Med. 1992;85(4):238-9.

19. Murray RN, Parker A, Kadakia SC, Ayala E, Martinez EM. Cytomegalovirus in upper gastrointestinal ulcers. J Clin Gastroenterol. 1994;19(3):198-201.

20. Taniwaki S, Kataoka M, Tanaka H, Mizuno Y, Hirose M. Multiple ulcers of the ileum due to Cytomegalovirus infection in a patient who showed no evidence of an immunocompromised state. J Gastroenterol. 1997; 32(4):548-52.

21. Klauber E, Briski LE, Khatib R. Cytomegalovirus colitis in the immunocompetent host: an overview. Scand J Infect Dis. 1998;30(6):559-64.

22. al Mahdy H. Cytomegalovirus colitis in immunocompetent individual. J Clin Pathol. 1998;51(6):475-6.

23. Suter WR, Neuweiler J, Borovicka J, Binek J, Fantin AC, Meyenberger C Cytomegalovirus-induced transient protein-losing hypertrophic gastropathy in an immunocompetent adult. Digestion. 2000;62(4):276-9.

24. Karakozis S, Gongora E, Caceres M, Brun E, Cook JW. Life-threatening cytomegalovirus colitis in the immunocompetent patient: report of a case and review of the literature. Dis Colon Rectum. 2001:44(11):1716-20.

25. Carter D, Olchovsky D, Pokroy R, Ezra D. Cytomegalovirus-associated colitis causing diarrhea in an immunocompetent patient. World J Gastroenterol. 2006;12(42):6898-9.

26. Morunglav M, Theate I, Bertin G, Hantson P. CMV enteritis causing massive intestinal hemorrhage in an elderly patient. Case Rep Med. 2010;2010:1-4.

27. Ko JH, Peck KR, Lee WJ, Lee JY, Cho SY, Ha YE, Kang Cl, Chung DR, Kim YH, Lee NY, et al. Clinical presentation and risk factors for cytomegalovirus colitis in immunocompetent adult patients. Clin Infect Dis. 2015;60(6):e20-6.

28. Bernard S, Germi R, Lupo J, Laverriere MH, Masse V, Morand P, Gavazzi G. Symptomatic cytomegalovirus gastrointestinal infection with positive quantitative real-time PCR findings in apparently immunocompetent patients: a case series. Clin Microbiol Infect. 2015;21(12):1121 e1121-7.

29. Clyde S Cl, Jie Lin Zhang: Cytomegalovirus. In: Principles and Practice of Infectious Diseases. Volume 2, Seventh Edition edn. Edited by Gerald L Mandell JEB, Raphael Dolin. Philadelphia, The United States: Churchill Livingstone Elsevier; 2010: 1971-1982.

30. Khan TV, Toms C. Cytomegalovirus colitis and subsequent new diagnosis of inflammatory bowel disease in an Immunocompetent host: a case study and literature review. Am J Case Rep. 2016;17:538-43.

31. Galiatsatos P, Shrier I, Lamoureux E, Szzlagyi A. Meta-analysis of outcome of cytomegalovirus colitis in immunocompetent hosts. Dig Dis Sci. 2005;50(4):609-16.

32. Soderberg-Naucler C, Fish KN, Nelson JA. Reactivation of latent human cytomegalovinus by allogeneic stimulation of blood cells from healthy donors. Cell. 1997;91(1):119-26.

33. Rafailidis PI, Mourtzoukou EG, Varbobitis IC, Falagas ME. Severe cytomegalovirus infection in apparently immunocompetent patients: a systematic review. Virol J. 2008:5:47. 
34. Hauser AB, Stinghen AE, Kato S, Bucharles S, Aita C, Yuzawa Y, Pecoits-Filho R. Characteristics and causes of immune dysfunction related to uremia and dialysis. Perit Dial Int. 2008;28(Suppl 3):S183-7.

35. Al-Omari A, Aljamaan F, Alhazrani W, Salih S, Arabi Y. Cytomegalovirus infection in immunocompetent critically ill adults: literature review. Ann Intensive Care. 2016,6(1):110.

36. Goodgame RW. Gastrointestinal cytomegalovirus disease. Ann Intern Med. 1993;119(9):924-35.

\section{Publisher's Note}

Springer Nature remains neutral with regard to jurisdictional claims in published maps and institutional affiliations.

Ready to submit your research? Choose BMC and benefit from:

- fast, convenient online submission

- thorough peer review by experienced researchers in your field

- rapid publication on acceptance

- support for research data, including large and complex data types

- gold Open Access which fosters wider collaboration and increased citations

- maximum visibility for your research: over $100 \mathrm{M}$ website views per year

At $\mathrm{BMC}$, research is always in progress.

Learn more biomedcentral.com/submissions 